J Chron Dis 1973, Vol. 26, pp. 595-611. Pergamon Press. Printed in Great Britain

\title{
SOCIOECOLOGICAL STRESSOR AREAS AND BLACK-WHITE BLOOD PRESSURE: DETROIT
}

\author{
Ernest Harburg*, John C Erfurt $\dagger$, Catherine Chapeł, louise S. Hauenstein§, \\ William J. Schull $\|$ and M.A. Schork 1
}

The University of Michigan, 405 South Fourth Street, Ann Arbor, Mich. 48103, U.S.A.

(Received 28 February 1972; in final form 23 May 1973)

\section{INTRODUCTION}

THERE is strong evidence that higher levels of blood pressure are related to higher rates of mortality from coronary heart disease and cerebrovascular attacks, or stroke [e.g. 1,2]. American Negroes have higher blood pressure levels, higher morbidity and mortality from hypertension, hypertensive heart disease, and stroke than their White compatriots [3]. The causes are unknown. This report examines socio-environmental differences between Black and White urban populations in relation to blood pressure. The data are from a project entitled 'Stress and Heredity in Negro-White Blood Pressure Differences' [4]. One of the major hypotheses in the project is examined here, namely, that urban socioecological areas which vary in rates of stressor conditions may have populations which vary in blood pressure levels.

The concept of 'stressors' from a social viewpoint, and their possible effects on the organism, is dealt with ably in several recent general reviews $[5,6]$. For adequate lists of recent references specifically relating stressor conditions to blood pressure, from a sociocultural view, see Henry and Cassel [7]; and from a socio-psychological view, see Kasl and Cobb [8]. In this study, we assume that socially disorganized life areas generate problem situations requiring adaptation more often and with less resources for solution than more organized areas. The rates of certain critical social conditions in given socioecological areas reflect the probability of inducing disequilibria in the local organisms. Thus, for example, both level of income and education, as well as marital stability and crime, must be considered in estimating relative degree of stress-inducing

\footnotetext{
* Research Associate, Department of Psychology and Department of Epidemiology, The University of Michigan.

†Research Associate in the Institute of Labor and Industrial Relations, The University of Michigan.

$\ddagger$ Research Associate, Medical Care Organization, School of Public Health, The University of Michigan.

\$Research Associate, Department of Psychology, The University of Michigan.

||Director, Center for Demographic and Population Genetics, Graduate School of Biomedical Sciences, The University of Texas-Houston.

ףProfessor of Biostatistics, School of Public Health, The University of Michigan. 
conditions present in local populations. It is important that these external conditions be measured independently of the emotional states of individuals in the local populace [9]. One study, using this framework, reports a relationship between the estimated rank of family disorganization for Blacks by counties in North Carolina and the mortality rate from cerebrovascular accidents [10]. There is evidence to assume that stroke rates are indicators of hypertensive blood pressure levels [11].

Other studies specifically describing blood pressure differences between rural-urban areas have been reported in different locales in the world. Five [12-16] report urban blood pressure levels higher than rural levels, two $[17,18]$ report them lower. Stressor conditions are suggested as being implicated in six of the seven studies; however, only two of the six studies measured aspects of stressor conditions within an urban environment. Thus, Scotch reports that for migrant Zulu adults residing in an urban area, certain social patterns (e.g. marital status, church membership, family type, income and clinic attendance) were associated with blood pressure levels. The point is explicitly made that 'a pattern of behaviour or social situation may or may not be stressful depending on the social context in which it occurs' (p. 1205) [19]. One recalls Kunin's intriguing findings that both Black and White nuns had significantly lower blood pressure levels than a comparison sample of working-class, urban females [20].

The second study measuring blood pressure and aspects of stressor conditions within an urban environment, by Langford and Watson [21], reports results on 1765 high school girls in Jackson, Mississippi. Initial results showed blood pressure differences by high school. This was interpreted as reflecting socioeconomic status (SES) differences and induced further analysis. SES levels for students were estimated by housing data, using as criteria: (1) the proportion of 'sound' housing units, (2) the per cent of dwelling units with greater than 1.00 person per room, and (3) average owner value of housing units, for city block areas where sample members lived. The results show that the lower the SES, the higher the blood pressure levels. It is also pertinent that, while Black females had higher blood pressure than White girls, nevertheless, the blood pressures of 'high' SES city Negro girls were approximately the same as those of rural White girls.

The present study was specifically designed to test whether or not blood pressure levels will vary predictably among four sex-race groups residing in the extremes of high and low stressor areas within an urban environment, and if so, are such differences attributable to any stronger hypothesized factors which may also vary by area, e.g. age, weight and so forth?

\section{METHOD}

\section{Selection of stress areas [22]}

There is much evidence that persons residing in 'inner city' areas exist in an environment that is sharply different from the 'outer city' and suburban areas. The latter areas exhibit performance rates in educational, recreational, sanitary and service facilities which indicate attainment of culturally valued levels of living. Conversely, inner city areas exhibit sharply lower attainment levels and in addition, repeatedly manifest higher rates of crime, divorce, unemployment and population density than outer city areas [23]. Detroit is no exception to these contrasts [24, 25]. It is assumed that such statistically different rates, at their end-points, indicate environments which vary objectively in chronic exposures to stressor events. We will call such kinds of different 
environments, High and Low Stress areas, and will now describe how such areas were selected.

Briefly, all the census tracts of Detroit were rank ordered by their 'stress scores'. These scores were computed as follows: first, the rates for selected variables which represented the concepts of economic deprivation, residential instability, family instability, crime and density were computed for each census tract in the city. The rates were then factor analyzed and the 382 census tracts were each assigned factor scores [26] for the two emergent oblique factors: socioeconomic status and instability. The factor scores were then separately rank ordered for all predominantly Black tracts (50 per cent Negro or more) and for all the residual White tracts. Then, within each ethnic group, census tracts for each factor score list were selected for having both the upper range for the instability score and the lower range for the SES scores-these tracts were labeled 'High Stress'. The converse was done to delimit the 'Low Stress' tracts. Data in Table 1, Part $\mathrm{C}$ indicate that the final selection of four primary study areas (Black High and Low Stress, White High and Low Stress) were in the extreme quartiles of factor scores. Secondly, the data in the main body of Table 1 serve as a reliability check on actual rates of the study tract after its selection on the basis of factor scores. Other rates, e.g. school truancy, 'drop-outs', welfare registration, Aid to Dependent Children, etc., showed similar sharp expected differences and are not shown. Fig. 1 shows the location of the four areas in Detroit. It should be noted that both Low Stress areas are each single census tracts; both High Stress areas, however, are each four contiguous census tracts equivalent in social characteristics. In the latter areas, multiple tracts

TABle 1. RAtes for PRIMARY STRESS AREAS, DetroIt, 1965a

\begin{tabular}{|c|c|c|c|c|c|c|}
\hline \multirow{2}{*}{\multicolumn{2}{|c|}{ Characteristics }} & \multicolumn{3}{|c|}{ Black } & \multicolumn{2}{|c|}{ White } \\
\hline & & & High stress & Low stress & High stress & Low stress \\
\hline & Total dwelling units & & $(4118)$ & $(1910)$ & $(4410)$ & $(1811)$ \\
\hline \multirow{6}{*}{ (A) } & Socioeconomic variables & & & & & \\
\hline & 1. Median income & & $\$ 4627$ & $\$ 8670$ & $\$ 5417$ & $\$ 8030$ \\
\hline & 2. Median education (yr) & & $9.6 \mathrm{yr}$ & $13.2 \mathrm{yr}$ & $9.0 \mathrm{yr}$ & $11.7 \mathrm{yr}$ \\
\hline & 3. \% Unemployed & & $4 \%$ & $0 \%$ & $0 \%$ & $0 \%$ \\
\hline & 4. $\%$ Home ownership & & $19 \%$ & $92 \%$ & $40 \%$ & $90 \%$ \\
\hline & 5. $\%$ Professional $/$ managerial & & $9 \%$ & $49 \%$ & $7 \%$ & $19 \%$ \\
\hline \multirow{5}{*}{ (B) } & Instability variables & & & & & \\
\hline & 1. Adult crime rate (per 10,000$)$ & & 89.0 & 55.9 & 60.0 & 9.9 \\
\hline & 2. Juvenile crime rate (per 10,000 ) & & 17.2 & 6.4 & 13.5 & 1.3 \\
\hline & 3. Marital instability & & $1: 2.9$ & 0.0 & $1: 12$ & 0.0 \\
\hline & 4. $\%$ in residence 5 yr or more & & $27 \%$ & $51 \%$ & $48 \%$ & $86 \%$ \\
\hline \multirow{7}{*}{ (C) } & Factor scores b & & & & & \\
\hline & 1. Socioeconomic Status & $\not$ & $=92$ & 117 & 96 & 111 \\
\hline & Range & \multicolumn{3}{|c|}{$(69-117)$} & \multicolumn{2}{|c|}{$(77-126)$} \\
\hline & Rank order \% & & Lowerc $35 \%$ & Upper $1 \%$ & Lower $21 \%$ & Upper $23 \%$ \\
\hline & 2. Instability & $\bar{X}$ & $=110$ & 98 & 99 & 93 \\
\hline & Range & \multicolumn{3}{|c|}{$(94-151)$} & \multicolumn{2}{|c|}{$(91-140)$} \\
\hline & Rank order $\%$ & & Upper $17 \%$ & Lower $14 \%$ & Upper $21 \%$ & Lower $11 \%$ \\
\hline
\end{tabular}

aThese data are from a 4 per cent sample of the City of Detroit by the Transportation and Land Use Study, except for crime data supplied by the City of Detroit Police Department.

bFactor Scores were obtained by factor analyzing rates of the variables presented across all 382 census tract areas in Detroit.

cThere was a rank-order tie of 15 tracts among Black, low socioeconomic census tracts. 


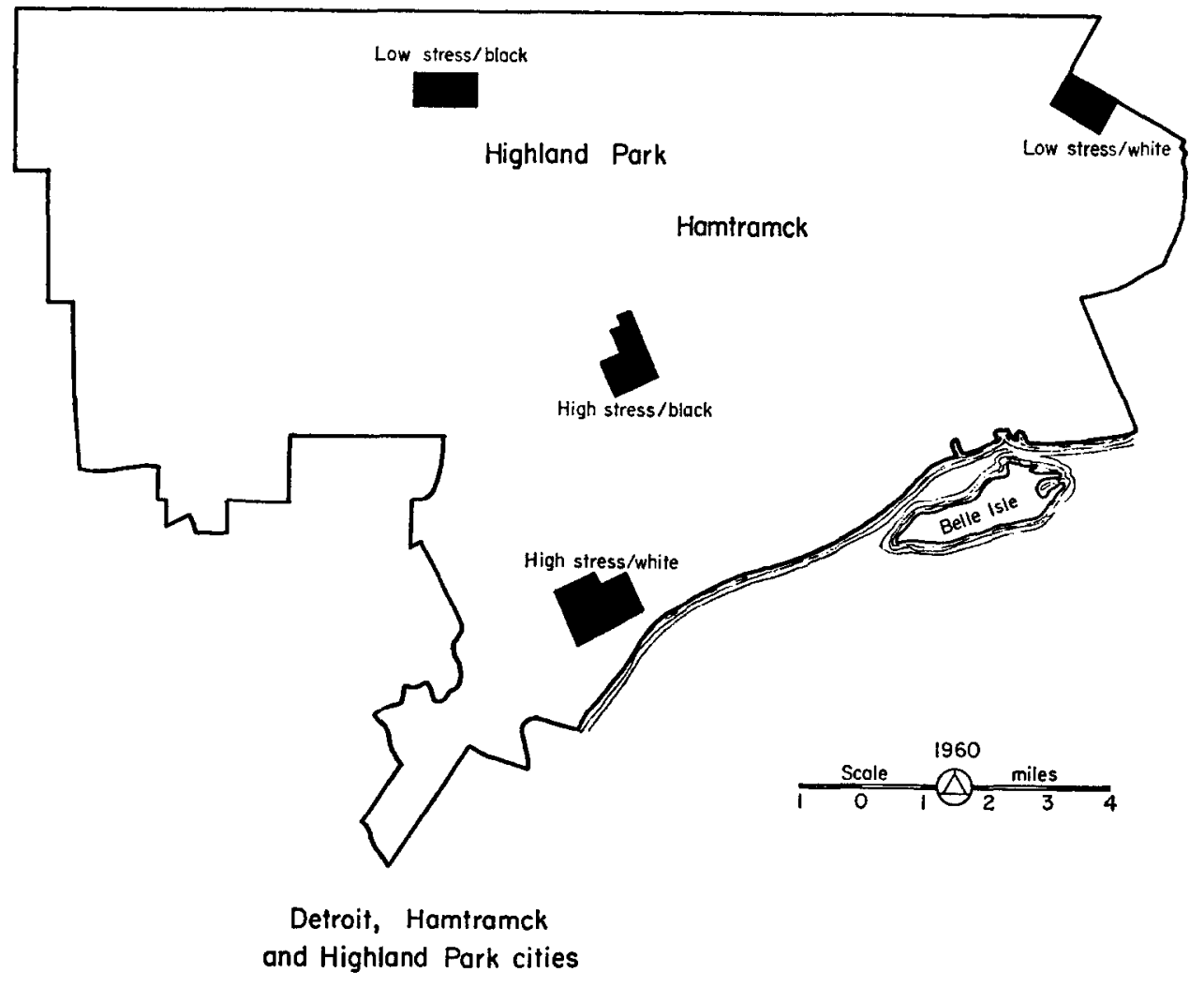

Fig. 1.

were required to increase the yield of families required by the genetic design in the larger Project.

\section{Selection of the sample}

One major purpose of the larger Project was to estimate the relative contributions of stress and heredity to blood pressure levels. The Ecological Sample, for purposes of this report, consists of persons who: (1) resided in one of the four stress areas; (2) were of the given race of that arca; (3) aged between 25 and $60 \mathrm{yr}$; (4) were married and living with spouse; and (5) had relatives (siblings and cousins) in the Metropolitan area [27]. The sampling and interviewing was carried out in two stages. First, in Stage $I$, a 'door-to-door' census was taken in each of the four stress areas to screen and classify potential sample members. The per cent interviewed of all inhabited dwelling units in the census was about 89 per cent; 'flat' refusals were about 2-3 per cent in each area. Next, each person classified as having the five sample traits already described ('potential' sample member) was visited by a trained interviewer. This verification interview checked the criteria traits of the person and the data on the relatives. If validated, we requested the person's cooperation in the study, and arranged an interview by a nurse. Next, in Stage $I$, trained nurses of the same race as the respondent were then randomly assigned to interview randomly selected, verified 'potentials' residing in both High and Low Stress areas, changing the area each week for each nurse. The non-interview rate for nurses was similar across all areas and averaged 
about 6 per cent. The final sample of persons having the desired traits within each of the eight sex-race-stress area groups, and the design of the analysis, is shown below:

\begin{tabular}{rrrrrrrrrr}
\hline & \multicolumn{3}{c}{ Males } & \multicolumn{3}{c}{ Ecological sample } & \multicolumn{3}{c}{ Females } \\
Black & \multicolumn{2}{c}{ White } & \multicolumn{2}{c}{ Black } & \multicolumn{2}{c}{ White } \\
High & Low & High & Low & High & Low & High & Low \\
stress & stress & stress & stress & stress & stress & stress & stress \\
\hline$N=$ & 118 & 134 & 120 & 120 & 128 & 128 & 130 & 122 \\
$X$ age $=$ & 40 & 40 & 40 & 43 & 42 & 40 & 41 & 44 \\
$X$ weight $=$ & 176 & 181 & 176 & 181 & 159 & 148 & 146 & 144 \\
\hline
\end{tabular}

\section{Measurement of blood pressure}

All nurse-intervicwers were carefully screened through a minimum of $20 \mathrm{hr}$ of training to both survey technique and a standard blood pressure technique [28] for the nine-month data collection (October 1968-June 1969). A reading was taken at the start of the interview, then, about 5-10 min later, and again, about $10 \mathrm{~min}$ later during the first $\frac{1}{2}$ hr of medical history. A standard new Baumanometer (mercury sphygmomanometer) was used, with Velcro cuff (at heart level), and all parts were checked each day for effectiveness [29]; nurse performance was quality controlled at various timepoints during the data collection by double stethoscope readings with the supervisor. Readings in the home were taken on the left arm, with the respondent seated and arm resting on a table. First, a palpatory pressure was read to relax the person and to allow the nurse to estimate the initial systolic reading. Next, an ausculatory reading was taken; systolic was recorded at the first sound and diastolic at the cessation of sound, or fifth Korotkoff point. A Latin-Square design was executed before field work by 15 nurses on 15 subjects in a classroom setting to test for both (a) nurse and (b) instrument differences. No significant differences were found for either 'main effect' for either systolic or diastolic pressures. However, digit-preference differences were present, about 30 per cent of readings ended in ' 0 '. Our design (from the Pilot Study) required that blood pressure readings be calculated as the Mean of the first three readings. This statistically eliminated digit preference differences from subsequent analyses and reduced the errors of instability in a single, casual reading.

Analyses are performed with four dependent variables: Mean Systolic, Mean Diastolic, 4 Category Systolic and 4 Category Diastolic. (1) Mean Systolic: Mean Average of the first three systolic readings taken in the first $\frac{1}{2} \mathrm{hr}$ of interview, about 10 min apart; (2) Mean Diastolic: the mean average of the first three diastolic (fifth phase) readings; (3) 4 Category Systolic and (4) 4 Category Diastolic: groupings having clinical import-for Systolic (a) $\leq 119 \mathrm{~mm}$; (b) 120-139 mm; (c) 140-159 mm; (d) $160+\mathrm{mm}-$ for Diastolic (a) $\leq 83 \mathrm{~mm}$; (b) $84-89 \mathrm{~mm}$; (c) $90-94 \mathrm{~mm}$; and (d) $95+$ $\mathrm{mm}$. These are coded as Low Normal, Normal, Borderline and Hypertensive. These categories can be interpreted either as 'grouped levels' of blood pressure, or as clinically heuristic devices suggested by the American Heart Association [30]. Regardless of which interpretation the reader prefers, they are both indicators of level of risk for mortality from coronary and cerebral attacks [31]. 


\section{Statistical tests}

In this report, differences between means of social groups were tested with a 1-tail test. The direction of blood pressure differences was predicted to be as follows: (1) with race and sex constant, then the Alternative Hypothesis [32] is 'Mean, High Stress > Mean, Low Stress'; and (2) with sex constant and race differing, then, 'Mean, Black > Mean, White', regardless of Stress area. For the former case, a theory of stress prevails, while for the latter case, prior empirical results in the United States prevail. Furthermore, we prefer to risk accepting possibly false trends than to reject the possible true trends. For the reporting of further results in this paper therefore, the reader may assume a one-tail test unless explicitly stated otherwise.

\section{RESULTS}

\section{Social characteristics of stress areas}

Some of the pertinent social factors of individuals in the four socioecological areas could be predicted from ecological rates or United States Census urban trends [23], e.g. in our sample, Blacks have higher per cent prior divorces and are more often Southern migrants; Black workers made the lowest income and are highest unemployed; and in this study's age group (25-59), almost twice as many Black women are working than White women. Certain other traits are local Detroit facts which should be noted: First, the White Low Stress sample is older, is $\frac{3}{4}$ Catholic, resides in an all-white area, 84 per cent were raised in the Detroit area, and average about $10 \mathrm{yr}$ in their residence. A large Northeastern area of the City where this area is encased also shares these traits. (Detroit is about 35 per cent Catholic). Other data, not shown, indicate strong anti-Black biases in this populace. Almost conversely, the Black Low Stress sample is younger, is 91 per cent Protestant, resides in an area which in 1960 was all White and in the 1970 Census was 82 per cent Black; 80 per cent have lived there less than 5 yr. Furthermore, 72 per cent of the wives are working, either full or part-time, and 21 per cent, as professionals or managers. It must be added that this tract area in 1965 was not only at the top 1 per cent of all Black tracts on our Socioeconomic Status factor scores, but was also in the top 5 per cent for all 382 tracts in Detroit. The White High Stress area is half Protestant, half Catholic, mostly workers, one-third from the South, one-fourth in apartment houses (about 65 per cent of Detroiters reside in single-family dwelling units). Both White areas were $99+\%$ White in 1960 and in 1970, even though the Negro population of Detroit rose from 28 to 44 per cent in this decade. For the Black High Stress area, as expected, this area of all groups shows the lowest median income, Occupational Prestige Score and home ownership, and the highest per cent operatives and laborers and per cent family head unemployed (even in 1968). The usual discrepancy of higher education and lower income relative to the White working-class is also present. The residential mobility appears as high as the White High Stress-over two-fifths have changed residences within five years. There are other data which allow us to assume that much of this movement is either within the area or from equivalent areas in Detroit [33], especially for the Blacks moving from the path of 'urban renewal'. Finally, it should be noted that the Black High Stress area is contiguous to the '12th Street' tract in which the 'Detroit Rebellion' erupted in 1967, and where the Pilot Study was done in 1966-67 [34]. 


\section{Perception of neighborhood}

Do the residents of these stress areas vary in their perceptions of their neighborhood? Table 2 presents data testing the assumed link between the objective existence of rates of stressor events (already described) and the perception of threat and report of desirability of living in the area. Table 2 supports the expectancy of perceived differences between persons in High and Low Stress areas. Aspects of police service and housing discrimination separate Black and White perception, as would be expected from other surveys [35]. Most pertinent for this study, over three-quarters (77 per cent) and half ( 50 per cent) of the sample in the High Stress areas desired to move to a different neighborhood, compared with about one-quarter of persons in the Low Stress tracts [36].

\section{Stress areas and blood pressure}

Having described the social class and perceptual differences among our four stress areas, we then tested for differences in blood pressure. Data in Table 3 indicate that for

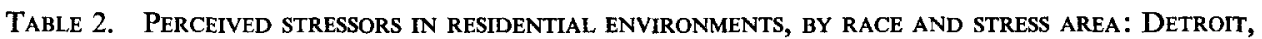
$1968-69$

\begin{tabular}{lcccc}
\hline & \multicolumn{2}{c}{ Black } & \multicolumn{2}{c}{ White } \\
Characteristics & High stress & Low stress & High stress & Low stress \\
& $(\mathrm{N}=246)$ & $(\mathrm{N}=262)$ & $(\mathrm{N}=250)$ & $(\mathrm{N}=242)$ \\
\hline
\end{tabular}

(A) Neighborhood threat

1. Neighborhood not too safe or not safe at all

2. Fairly or very likely be beaten or robbed when out at night

3. In last year, in neighborhood, heard of or know about:
(a) fights w/ weapon
(b) person assaulted or beaten
(c) female threatened

$\begin{array}{rrrr}66 \% & 9 \% & 30 \% & 2 \% \\ 65 \% & 25 \% & 44 \% & 13 \% \\ & & & \\ 55 \% & 9 \% & 34 \% & 6 \% \\ 60 \% & 17 \% & 58 \% & 16 \% \\ 40 \% & 15 \% & 32 \% & 9 \% \\ & & & 1 \% \\ 29 \% & 17 \% & 7 \% & \\ & & & 71 \% \\ 25 \% & 52 \% & 58 \% & \end{array}$

(B) Residential stability

1. Not too satisfied or not satisfied at all with neighborhood leisure time outlets

2. Dissatisfied or very dissatisfied w/ present house/apartment

3. Mostly not like or not like at all living in present neighborhood

4. Want to move fairly or very much

5. Owner refuse to sell to $\mathbf{R}$ due to $R$ 's religion, race, nat'l origin is somewhat, fairly, or very likely

$\begin{array}{llll}66 \% & 26 \% & 36 \% & 16 \% \\ 29 \% & 3 \% & 13 \% & 4 \% \\ 47 \% & 2 \% & 16 \% & 1 \% \\ 77 \% & 26 \% & 50 \% & 29 \% \\ 69 \% & 64 \% & 13 \% & 4 \%\end{array}$




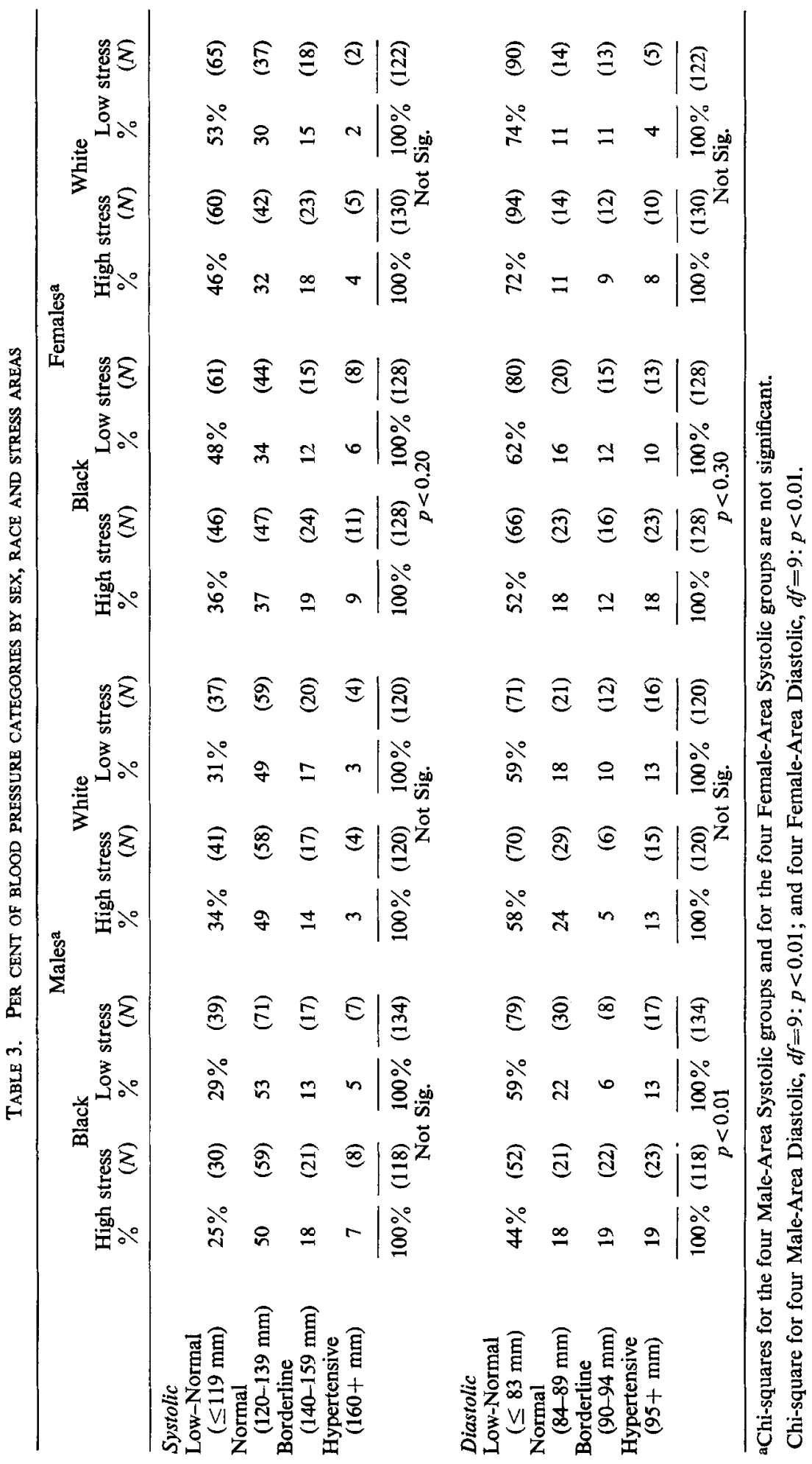


males, when systolic and diastolic categories are related to race-area groups, the trends show that High Stress Black males have the highest per cent of higher readings $(140+/ 90+)$ compared to the other three male race-area groups, which appear quite similar to each other. This trend is less apparent for systolic categories, than for diastolic $(p<0.01)$. Next, within race, High Stress Black males have higher proportions of Borderline and Hypertensive diastolic categories (38 per cent) than Low Stress Black males $(19$ per cent; $p<0.01)$. No differences appear between the White High and Low Stress areas. For females, the trends are similar, within race and between areas, but at a reduced contrast for both systolic and diastolic pressures. Black High Stress females had the highest percent of Diastolic Borderline and Hypertensive (30 per cent), than Black Low Stress (22 per cent), or White High (17 per cent) or White Low $(15$ per cent $)(p<0.01)$. These trends were not significant, but were similar for Systolic categories. These figures do not take into account other population differences, such as age and weight.

\section{Effects of adjustments for other factors}

Are such trends due to age and overweight differences among the areas? The data show, for example, that High Stress Black females weigh more $(\bar{X}=159 \mathrm{lb})$ than either Low Stress Black females $(\bar{X}=148 \mathrm{lb})$ or White females $(\bar{X}$ about $144 \mathrm{lb})$; and that White Low Stress females are slightly older $(\bar{X}=43.9$ yr $)$ than White High Stress females $(\bar{X}=41.2 \mathrm{yr})$. Furthermore, while categories of blood pressure are important to know, blood pressure levels must also be a focus of inquiry. For each sex-race-area group, we computed the means and standard errors for Observed Blood Pressure and then adjusted these means for seven major covariates: age, overweight, ponderal index, season of year, time of interview, hours since last meal, and rated tension at readings (See Appendix A). These seven major covariates were selceted to represent known factors related to blood pressure. The age, overweight and ponderal index variables are standard controls. The variables labeled season, time of interview, hours since meal, and rated tension may be viewed as 'undesired noise' in measuring blood pressure. Statistical adjustment for the seven covariates of the mean pressures in High and Low Stress groups was computed by a standard stepwise multiple regression technique within a one-way analysis of covariance model (BMDX82 program); these adjusted means were tested for significance using race-sex group correlations $(N=250)$ [37].

\section{Adjusted blood pressure for males}

Turning attention now to Fig. 2, the major findings are, first, Black High Stress males have higher mean observed blood pressure levels than their Low Stress counterparts. After adjustment for the major seven covariates (already described), the differences remain but are less for Systolic $(p<0.05)$ than for Diastolic $(p<0.02)$. Second, $t$-tests (not shown) on the adjusted means reveal there are no differences between White males by stress area, nor between Low Stress Black males and the two White male groups for three of four comparisons. The one exception to this trend is that Black Low Stress males have slightly higher Diastolic readings after adjustment than White High Stress males. This difference is reduced and non-significant when variance due to age, overweight and socioeconomic status are adjusted for, i.e. family income, education level and occupational prestige level. 


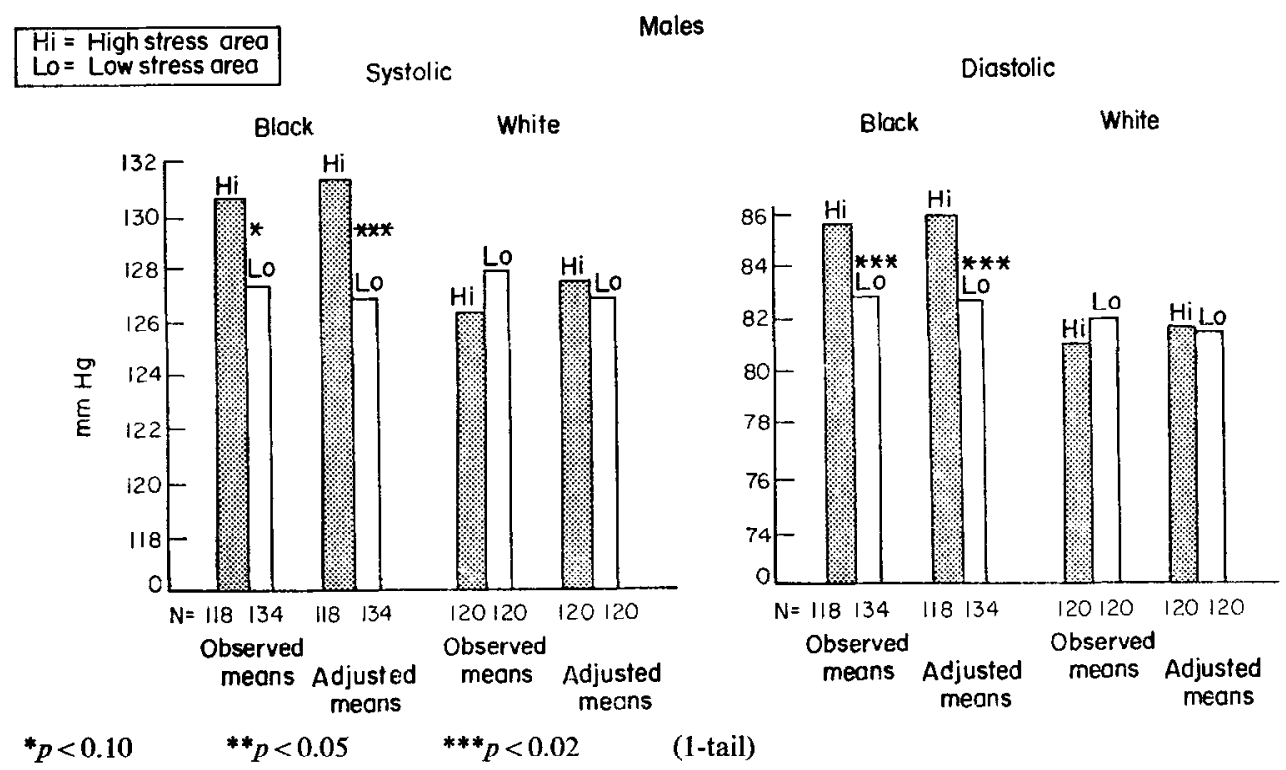

Fig. 2. Mean blood pressure levels of sex and race by stress area: Means observed and adjusted for age, overweight, ponderal index, season, time of day, time since last meal and tension.

\section{Adjusted blood pressure for females}

Figure 3 describes blood pressure levels among females. For observed pressures, the Black High Stress females have significantly higher levels than their Black Low Stress sisters and there are no differences in readings between High and Low Stress White females. When variance due to the major covariates is adjusted, the rank order of levels remain, but the differences between groups change. Now, there are no significant differences between High Stress and Low Stress Black females $(p>0.10)$ and differences in Systolic levels appear at the 0.05 level between the High and Low Stress White females. Inspection of data, not shown, suggests that this new effect for Blacks was largely due to a higher per cent overweight among Black High Stress females. (These mean weights have already been described). Data in Fig. 3 further show that Black females, regardless of stress area, have higher blood pressure levels than White females.

\section{Effect of high stress}

From data in Figs. 2 and 3 it can be seen that in eight comparisons, for Systolic and Diastolic levels, each of the High Stress areas has a higher adjusted blood pressure level than the matched Low Stress area, even though such differences are statistically significant in only three cases. It is also of note that the Black High Stress males have the highest levels and the White Low Stress females have the lowest pressures of all the eight social groups. The size of differences between stress area blood pressure means is not of import from a clinical and individual point of view; from an epidemiological viewpoint, however, the constant direction of differences across eight comparisons is suggestive. The magnitude of diastolic mean differences between Black High and Low Stress males is $3.1 \mathrm{~mm}$ and between Black High and Low Stress females is $2.9 \mathrm{~mm}$. 


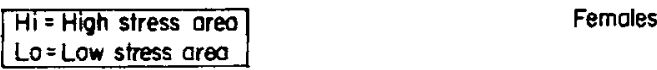

Systolic

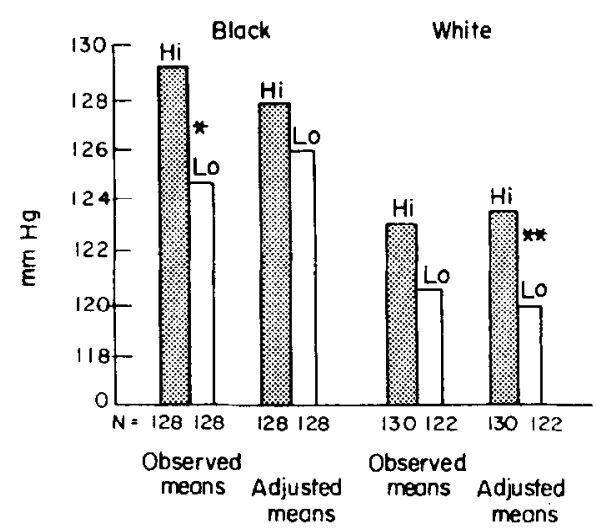

Diastolic

Black White

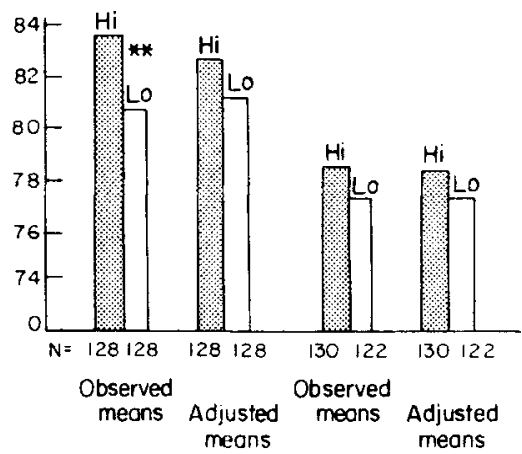

${ }^{*} p<0.10$

${ }^{* *} p<0.05$

${ }^{* * *} p<0.02$

(1-tail)

FIG. 3. Mean blood pressure levels of sex and race by stress area: Means observed and adjusted for age, overweight, ponderal index, season, time of day, time since last meal and tension.

For comparison, the differences between diastolic mean pressures between Black and White males in the USPHS Survey [45] across all ages was $4.4 \mathrm{~mm}$ and between Black and White females, $5.7 \mathrm{~mm}$. Not much of the variance of blood pressure is accountable for by the dichotomy of Black and White but the constant direction of difference is stable across many surveys. We suggest this constant effect may also hold for differences within racial groups who vary on socioecological status levels.

The fact that blood pressure levels are highest among Black High Stress males of all social groups prompted examination of the relation of age and overweight to pressures among this group. Figure 4 reveals that the effects of stress area on Black males are

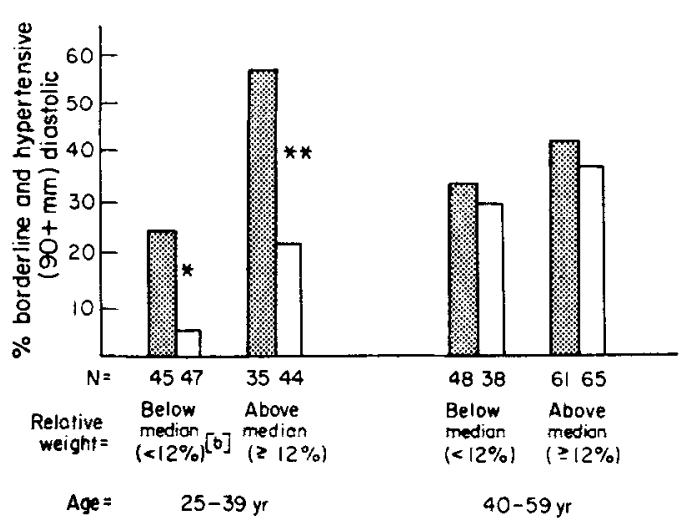

High stress

Low stress

Fig. 4. Age, overweight, stress area and diastolic blood pressure: Black males[a].

${ }^{*} p<0.05$ (Chi-square) $\quad{ }^{* *} p<0.01$

[a] Index unrelated or male spouse of female index cases were used in this table to increase the $N$ in the categories.

[b] Black males were categorized by Percent Relative Weight above or below the median for the total Ecological Sample (Median $=12 \%$ overweight; $n=1000$ ) 
manifest primarily among the younger men $(\leq 39)$; whether or not the men are overweight, the young High Stress Black men have $2 \frac{1}{2}$ times as much per cent Borderline and Hypertensive as do the young Low Stress Black men. A 'stressor hypothesis' would expect that blood pressure levels should rise at earlier ages for High Stress Blacks than Low Stress, as implied by Langford and Watkins [21]. This idea seems tentatively supported by the present findings. Tests for age-stress area interaction, however, were not significant. In Fig. 4, attention should also be called to the 'Older, Overweight' group where no stress area differences in per cent Borderline and Hypertensive categories are found for Black males. This same lack of stress area difference for older, overweight respondents also holds for Black females, White males and White females.

\section{DISCUSSION}

\section{Stressor areas and blood pressure}

In a correlational analysis such as this, no claims are made for causality; but clues as to where to look and what to look for in a well-designed prospective inquiry in natural experimental conditions should benefit by our framework and experience. The social stressor hypothesis which served to guide the design and analysis has helped derive the idea that 'socioecological niche' is a critical part of the environment and is associated with high blood pressure in specificd populations. This hypothesis explicitly assumes that even when the populace of an area is transient, as long as structural conditions related to socioeconomic level and instability remain constant, then (1) the majority of the 'turnover' population will be equivalent in social parameters and (2) will collectively behave or respond in equivalent patterns. Thus, general social statuses (race, sex, social class) are prescribed or achieved within the national and urban social structure; but for members of a given status group there is a limited number of available residential areas. We chose to assume in this study, and it can be tested in other studies prospectively or retrospectively, that, for example, the Black IIigh Stress males and females have only a small number of residence areas in Detroit to actually live in, and another set of areas they can not live in; this would hold for our White High Stress persons, and both Low Stress race-sex groups [38]. Thus, for example, our Pilot Study in 1966-67 was done in other census tracts, necessarily close to the Major Study areas because selected by factor scores of extreme ranking. The results were similar in both the Pilot Study and the present one: the Low Stress Blacks had a significantly lower per cent of Hypertensive blood pressure than did the High Stress Blacks [46].

One can also infer from the idea of niche that High Stress Blacks raised from early infancy and remaining in the city as adults should show higher blood pressure levels at an earlier age than Black Low Stress adults. In the present data the relation of age and pressure levels was in the expected direction for Black adults within both the under $30-y r$ old and under 40-yr old groups. Furthermore, the report of being raised in Detroit rather than migrating was significantly associated with higher levels for Black males contrary to other data [39]. Black High Stress males under 40 and overweight had a significantly higher per cent of Hypertensive and Borderline levels than Black Low Stress males, who did not differ from White Low Stress males by blood pressure categories. 
The opposing trends to this hypothesis are of course evident from our data. Even though the High Stress areas had higher levels of blood pressure, adjusted for area differences in age, overweight and artifacts of readings, yet White High Stress males were not significantly higher than their Low Stress counterparts and Black Low Stress males had slightly higher observed Diastolic levels than White High Stress men. Or again Black females did not differ across area for adjusted levels, and had higher adjusted levels than White females regardless of area. Conversely, however, White High Stress females had significantly higher Systolic levels than White Low Stress women, who in turn had the lowest pressures of all eight social groups and lived under the lowest stressor conditions. These variations encourage further use of stress areas as a factor in locating variations in blood pressure, and indeed, of other health risk factors such as overweight and smoking.

\section{Mobility factors}

It is important to recall that all the Low Stress Blacks had moved into the area after June, 1960 and most after 1965 [40]. In fact the Black Low Stress males and females both in the Pilot Study and in this present study had moved into a prior all-white area relatively recently before the two surveys. The average years in residence for the Pilot was 6.1 and for this study was 2.8. The Black Low Stress residents' educational levels, occupational and income levels were of course significantly higher than their High Stress Black comparison groups. The move into the Low Stress neighborhood therefore made their residential status congruent with their socioeconomic status. As a group these recent migrants to Low Stress areas have lower blood pressure levels than their High Stress counterparts. We can infer speculatively that upward social mobility as indicated by moving to a Low Stress neighborhood may not be a life-change event adverscly affecting blood pressurc [41]. A follow-up study of such a 'nouvcau' population matched with middle-class Blacks in both an 'old, settled' area and a High Stress area would allow testing of several hypotheses regarding social mobility, neighborhood cohesiveness, and personal coping styles with blood pressure and other health factors [42]. It is pertinent that such a new Black, middle-class group is now developing and establishing their niche in the urban scene in most major cities in the United States due to rising political, economic and social power. Thus such prospective studies are feasible and important for health as well as other areas of understanding.

Finally we know that within our High and Low Strcss areas, subgroups vary in thcir degree of control of socioeconomic resources, perhaps associated with 'mini-niches' or localized neighborhoods within the Stress area. These latter stress areas are considered only relatively homogeneous for comparison purposes. Again, more inquiry and analyses are called for to examine these sub-environs.

\section{CONCLUSIONS}

Returning then to the major hypothesis that blood pressure levels will vary with extremes of strcssor conditions in socioccological arcas, we can conclude that the data lend partial support for the utility of this approach. The first finding shows higher blood pressure levels for Black males in the High Stress than in the Low Stress areas, (both in the Pilot Study and in this study) and helps to focus on relevant sections of the environment within which further clues might be located. The second finding is that Black Low Stress males do not differ in levels from White Low Stress males. The third 
finding is that White High Stress females show higher Systolic levels than White Low Stress women. The fourth result is that for Observed blood pressure levels, Black High Stress females have significantly higher levels than Black Low Stress females.

On the other hand, the evidence is clear that Black subsets are more vulnerable to higher blood pressure than Whites. The finding that Black High Stress males show 38 per cent in the Borderline and Hypertensive categories of blood pressure compared to about 18-23 per cent in the other three male race-area groups indicates that higher mortality risks are involved [43, 44]. Black females show higher mean pressure levels than White women regardless of Stress area. The evidence of such Black and White differences in levels has already been well documented in other studies [45], but the further evidence that this study presents is that blood pressure differs within Black and within White subgroups. It bears repeating that for observed blood pressure levels, Black Low Stress females had significantly lower levels than Black High Stress females, who are typically an overweight social group in American, urban, working-class niches $[3,20]$.

\section{SUMMARY}

1. Blood pressure does appear to vary with 'socioecological niches' or combinations of sex, race and residence, which reflect social class position as well as degree of social stressor conditions. Black High Stress males had higher adjusted levels than Black Low Stress males, while White High Stress females had higher adjusted pressures than White Low Stress females. Black High Stress females had significantly higher observed levels than Black Low Stress females.

2. Black High Stress males had a significantly higher per cent of Borderline and Hypertensive blood pressure than other male race-area groups; White Low Stress females had the lowest of all eight sex-race-stress area groups.

3. For Black males, the younger, overweight High Stress residents had significantly higher Borderline and Hypertensive levels than did a similar Black Low Stress subgroup. Further, for both groups, being raised in Detroit and not migrating from elsewhere was related to higher readings. Tests for age-stress area interaction, however, were not significant.

Acknowledgements-A project as large as this must necessarily draw on the knowledge and skills of many agencies and persons. Acknowledgement of support to all is not possible; therefore the following list is a partial one.

Initial support in the form of seed money from the Office of Research Administration at The University of Michigan was critical in allowing this project to start. Our special thanks to Dr. Rudolph Schmerl. Dr. Samuel Fox's encouragement, funds from the Center for Chronic Disease Control, U.S. Public Health Service, and Mr. Robert Thorner's administrative skills within this Center, made the pilot survey viable.

Local resources of The University of Michigan in Ann Arbor have also been utilized in various ways with an equally high degree of cooperation. Informal consultation with a core group of authorities in ecology, biostatistics, hypertension, survey methods, sampling, and human genetics has been established for the duration of the Project. The computer facilities of The University of Michigan, the Institute for Social Research, and Wayne State University, including program consultation, have been used extensively.

Active consultants to this Project include: Dr. Jeremiah Stamler, Dr. Sibley W. Hoobler, and Dr. Theodore M. Newcomb. Other persons informally consulted were: Dr. Frederick Epstein, Dr. Otis D. Duncan, Dr. J. E. Keith Smith, and Dr. John Scott. They each have contributed much to this Project. Our special thanks to Dr. Stevo Julius and Dr. Robert Smith. We appreciate the risk-taking of Drs. Adrian Ostfeld and John Cassel. 
Cooperation from local agencies in Detroit has been superb. The Visiting Nurses' Association and the City Department of Health were most helpful in recruitment, and in solving minor problems. The City of Detroit, Department of Police, has furnished through its statistical units all the crime and delinquency records requested, in an efficient and most pleasant manner. The Mayor's Committee for Community Renewal Program has been most helpful in every request for data, maps, etc., made by Project personnel. Wayne State University campus facilities and graduate students' aid were arranged by the Department of Sociology and Anthropology, which also allowed use of a field office in the department, and appointed the Project Director an Adjunct Professor. Wayne State University provided facilities for training purposes, and facilitated administrative matters. Other agencies aiding the Project were the City of Detroit Planning Commission and the Metropolitan Services Agency. Many persons in Detroit have been consulted on a variety of problems, and all have freely given of their time and ideas.

The public health nurses who actually collected the data through snow, rain and high stress areas did an excellent job, guided by two superb nurse-supervisors: Mrs. Mildred Harvin (Pilot Study) and Mrs. Revera Munce (Major Study).

Our Detroit Advisory Committee must be thanked for their time, helpful criticisms and support: Dr. Mel Ravitz, Dr. Francis Kornegay, Dr. John Caldwell, Miss Sylvia Peabody, Dr. Leonard Moss, Dr. Ross Stagner, Dr. Robert Smock, Mr. Homer Hall, and Dr. Milton Palmer.

Appreciation must also be expressed to Ms. Karen Donahue, Ms. Eileen Kavanagh, and Mr. Robert Colman for office and data processing work required by this Project.

Finally, we must express our appreciation for additional grants of support from the Michigan Heart Association, the National Association of Mental Health, Inc., and the Fannie E. Rippel Foundation, at critical periods of work.

\section{REFERENCES}

I. Kannel WB, Schwartz MJ, McNamara PM: Blood pressure and the risk of coronary heart disease: The Framingham Study. Dis Chest 56: 51, 1969

2. Baker AB, Resch JA, Loewenson RB: Hypertension and cerebral atherosclerosis. Circulation 39: 701-710, 1969

3. Stamler J: Lectures in Preventive Cardiology. New York, Grune and Stratton, 1967

4. The sponsoring agencies for this project have been: National Center for Chronic Disease Control, USPHS, No. CD 00209-01, 02, 03 (1/1/66-12/31/67; 5/1/68-4/30/69);

National Center for Health Services, Research and Development, USPHS, No. HS 00164-04 $(05 / 01 / 69-04 / 30 / 70)$;

Michigan Heart Association Emergency Grant (7/1/69-6/30/70);

National Heart \& Lung Institute, USPHS, No. HE 13329-01, 02, 03, (05/01/70-04/30/73).

Fannie E. Rippel Foundation (10/1/72-12/30/73)

5. World Health Organization: Society, stress, and disease. WHO Chronicle 25: 168-178, 1971

6. Levine S, Scotch NA: Social Stress. Chicago: Aldine, 1970

7. Henry JP, Cassel JC: Psychosocial factors in essential hypertension: Recent epidemiologic and animal experimental evidence. Am J Epidem 90: 171-200, 1969

8. Kasl SV, Cobb S: Blood pressure changes in men undergoing job loss: Preliminary report. Psychosom Med 32: 19-38, 1970

9. Cassel J: Appraisal and implications for theoretical development. In Social stress and cardiovascular disease. Milbank Memorial Fund Quarterly, Syme SL and Reeder LG (eds). Vol. 45: Part 2 (entire issue) 1967

10. Neser WB, Tyroler HA, Cassel JC: Social disorganization and stroke mortality in the Black population of North Carolina. Am J Epidem 93: 166-175, 1971

11. World Health Organization Regional Office of Europe. Report of the WHO meeting on the prevention, treatment and rehabilitation of cerebrovascular disease, Monte Carlo, Monaco, 25-29 May 1970; Report of the WHO meeting of investigators on control of stroke and hypertension in the community, Geneva, Switzerland, 22-26 February 1971

12. Scotch N: Sociocultural factors in the epidemiology of Zulu hypertension. Am $\mathbf{J}$ Publ Hith 53: 1205,1963

13. Garcia-Palmieri MR, Costas R, Jri, Cruz-Vidal M et al: Risk factors and prevalence of coronary heart disease in Puerto Rico. Circulation 42: 541-549, 1970

14. Berkson DM, Stamler J, Lindberg HA et al: Socioeconomic correlates of atherosclerotic and hypertensive heart diseases. Ann NY Acad Sci 84: 835-850, 1960

15. Tseng W: Blood pressure and hypertension in an agricultural and a fishing population in Taiwan. Am J Epidem 86: 513-525, 1967

16. Langford HG, Watson RL: A rural-urban difference in blood pressure. Clin Res 14: 82, 1966 
17. Pukhlev A, Astrug A, Paskalev T et al: Epidemiological studies of blood pressure in Bulgaria. Cor Vasa 8: 1-9, 1966

18. Miall WE, Kass EH, Ling J et al: Factors influencing arterial pressure in the general population in Jamaica. Brit Med J 2: 497-506, 1962

19. Scotch NA, Geiger HJ: The epidemiology of hypertension: A review with special attention to psychologic and sociocultural factors. II. Psychologic and sociocultural factors in etiology. J Chron Dis 16: 1183-1213, 1963

20. Kunin CM, McCormack RC: An epidemiologic study of bacteriuria and blood pressure among nuns and working women. New Engl J Med 278: 635-642, 1968

21. Langford HG, Watson RL, Douglas BH: Factors affecting blood pressure in population groups. Trans Ass Amer Physicians 81: 135-146, 1968

22. Erfurt J, Harburg E, Rice R: A method for selection of census tract areas differing in ecological stress (multilith report), 1970

23. Bureau of Labor Statistics, No 332: Social and economic conditions of Negroes in the United States in current population reports. Washington, DC, Superintendent of Documents, Series P-23: No. 24, 1967

24. Detroit Urban League, Research Department: The Detroit Low-Income Negro Family, 1966

25. United Community Services of Metropolitan Detroit: Social Characteristics of Communities in the Detroit Area, 1963

26. Harmon HH: Modern Factor Analysis. Chicago: University of Chicago, 1960

27. Harburg E, Erfurt JC, Schull WJ, Schork, MA, Colman R: Heredity, stress and blood pressure, A family set method. I: Study aims and sample flow (Submitted for publication)

28. Kirkendall WM, Burton AC, Epstcin FH et al: Recommendations for human blood pressure determination by sphygmomanometers. Circulation 36: 980-988, 1967; See also Weinstein BJ, Epstein FH et al: Comparability of criteria and methods in the epidemiology of cardiovascular disease. Circulation 30: 643-653, 1964

29. Wilcox J: Observer factors in the measurement of blood pressure. Nursing Res 10: 4-17, 1961

30. Epidemiology of cardiovascular diseases methodology-hypertension and arteriosclerosis: report of conference, Princeton, New Jersey, 24-26 April 1959. Supplement to Am J Publ Hith and the Nation's Hlth 50: 1-124, 1960

31. Kannel WB, Gordon T, Schwart MJ: Systolic vs diastolic blood pressure and risk of coronary heart disease: The Framingham Study. Am J Cardiol 27: 335-346, 1971

32. Hays WL: Statistics for Psychologists. New York: Holt, Rinehart and Winston, 1963, Chapter 9

33. Mayer AJ, Hoult TF: Race and Residence in Detroit. Urban Research Laboratory, Institute for Urban Studies, Detroit, Wayne State University, 1962

34. Report of the National Advisory Commission on Civil Disorders. New York: Bantam Books, 1968

35. Detroit Urban League: A Survey of Attitudes of Detroit Negroes After the Riot of 1967 and Return to 12th Street: A Follow-Up Survey of Attitudes of Detroit Negroes, October, 1968. Coordinated with the Detroit Free Press.

36. Kasl SV, Harburg E: Perceptions of the neighborhood and the desire to move out. J Am Inst Plan Sept, 1972

37. Winer BJ : Statistical Principles in Experimental Design. New York: McGraw-Hill, 1962. Chapter 2.

38. McAllister RJ, Kaiser EJ, Butler EW : Residential mobility of blacks and whites: a national longitudinal survey. AJS 77: 445-456, 1971

39. Stamler J, Berkson DM, Lindberg HA et al: Socioeconomic factors in the epidemiology of hypertensive disease. In: The Epidemiology of Hypertension, Stamler et al (eds), op cit. 289-313.

40. Wolf EP, Lebeaux CN: Change and Renewal in an Urban Community: Five Case Studies of Detroit. New York, Praeger, 1969. See esp. Part I

41. Holmes TH, Rahe RH: The social readjustment rating scale. J Psychosom Res 11: 213-218, 1967

42. Harburg E, Erfurt JC, Hauenstein LS, Chape C, Schull WJ, Schork MA: Socioecological stress, suppressed hostility, skin color and black-white male blood pressure: Detroit. Psychosom Med 35: 276-296, 1973

43. Julius S, Schork MA: Borderline hypertension-a critical review. J Chron Dis 23: 723-754, 1971

44. Lew EA: Blood pressure and mortality-life insurance experience. In: The Epidemiology of Hypertension, Stamler et al (eds), op cit. 392-396.

45. National Center for Health Statistics: Blood pressure of adults by race and area, United States 1960-1962. Washington, DC, Superintendent of Documents, Series 11: No. 5, 1964

46. Harburg E, Schull WJ, Erfurt JC et al: A family set method for estimating heredity and stress. I. A pilot survey of blood pressure among Negroes in high and low stress areas, Detroit, 196667. J Chron Dis 23: 69-81, 1970 


\section{APPENDIX A}

\section{CODES FOR CONTROL VARIABLES}

1. Age: In years

2. Overweight: from Metropolitan Life Ideal Weight Tables

3. Ponderal Index: Height divided by the cube root of weight; ectomorphic to endomorphic

4. Season: (1) April-June (warm); (2) October-December; (3) January-March (cold). [Mean temperatures for each month were obtained from Local Climatological Data of the U.S. Department of Commerce, Environmental Data Service. The three seasonal groupings were derived from these temperature readings]

5. Time of Day: Hour interview started, $24-\mathrm{hr}$ clock; early to late

6. Time Since Last Meal: $(0)<1 \mathrm{hr}$ to $(8) 8$ or more hr

7. Rated Tension at Time of First Reading: Nurse rating: (0) No (1) Yes 